\title{
Resveratrol, a Natural Antioxidant, Has a Protective Effect on Liver Injury Induced by Inorganic Arsenic Exposure
}

\author{
Zhigang Zhang, ${ }^{1}$ Li Gao,, Yanyan Cheng, ${ }^{1}$ Jing Jiang, ${ }^{1}$ Yan Chen, ${ }^{1}$ Huijie Jiang, \\ Hongxiang Yu, ${ }^{1}$ Anshan Shan, ${ }^{2}$ and Baojing Cheng ${ }^{2}$ \\ ${ }^{1}$ College of Veterinary Medicine, Northeast Agricultural University, Harbin 150030, China \\ ${ }^{2}$ Laboratory of Molecular Nutrition and Immunity, The Institute of Animal Nutrition, \\ Northeast Agricultural University, Harbin 150030, China \\ Correspondence should be addressed to Zhigang Zhang; zhangzhigang@neau.edu.cn
}

Received 28 February 2014; Revised 5 July 2014; Accepted 7 July 2014; Published 24 July 2014

Academic Editor: Sophia Antimisiaris

Copyright (C) 2014 Zhigang Zhang et al. This is an open access article distributed under the Creative Commons Attribution License, which permits unrestricted use, distribution, and reproduction in any medium, provided the original work is properly cited.

\begin{abstract}
Resveratrol (Rev) can ameliorate cytotoxic chemotherapy-induced toxicity and oxidative stress. Arsenic trioxide $\left(\mathrm{As}_{2} \mathrm{O}_{3}\right)$ is a known cytotoxic environmental toxicant and a potent chemotherapeutic agent. However, the mechanisms by which resveratrol protects the liver against the cytotoxic effects of $\mathrm{As}_{2} \mathrm{O}_{3}$ are not known. Therefore, in the present study we investigated the mechanisms involved in the action of resveratrol using a cat model in which hepatotoxicity was induced by means of $\mathrm{As}_{2} \mathrm{O}_{3}$ treatment. We found that pretreatment with resveratrol, administered using a clinically comparable dose regimen, reversed changes in $\mathrm{As}_{2} \mathrm{O}_{3}-$ induced morphological and liver parameters and resulted in a significant improvement in hepatic function. Resveratrol treatment also improved the activities of antioxidant enzymes and attenuated $\mathrm{As}_{2} \mathrm{O}_{3}$-induced increases in reactive oxygen species and malondialdehyde production. In addition, resveratrol attenuated the $\mathrm{As}_{2} \mathrm{O}_{3}$-induced reduction in the ratio of reduced glutathione to oxidized glutathione and the retention of arsenic in liver tissue. These findings provide a better understanding of the mechanisms whereby resveratrol modulates $\mathrm{As}_{2} \mathrm{O}_{3}$-induced changes in liver function and tissue morphology. They also provide a stronger rationale for the clinical utilization of resveratrol for the reduction of $\mathrm{As}_{2} \mathrm{O}_{3}$-induced hepatotoxicity.
\end{abstract}

\section{Introduction}

Arsenic trioxide $\left(\mathrm{As}_{2} \mathrm{O}_{3}\right)$ is a known cytotoxic environmental toxicant and is used as a potent chemotherapeutic agent for acute promyelocytic leukemia (APL) and other cancers [1]. Retrospective case studies have shown a significant association between toxicity and the degree of retention of toxic compounds in tissues $[2,3]$. Arsenic interferes with a number of organ and body functions such as the central nervous system [4], liver, and kidney $[5,6]$. Liver as a major organ is responsible for the metabolism of drugs and is also the primary target for many toxic chemicals, with evidence of the highest concentration of total arsenic retention following acute arsenic toxicity [7]. In experimental animals, arsenicals induce liver injuries that cause alterations in the biochemical indices of hepatic functions, as well as changes in the morphology and apoptosis of liver cells $[8,9]$.
Both the toxic and therapeutic effects of arsenic are partially mediated by redox-sensitive enzymes and proteins. Ghosh et al. reported that the free radical mediated theory is one of the theories proposed to explain $\mathrm{As}_{2} \mathrm{O}_{3}$-induced injury [9]. Reactive oxygen species (ROS) are involved in normal cellular metabolism and signal transduction. However, they can cause damage at higher concentrations and induce several human pathologies, including liver cirrhosis and fibrosis [10]. Therefore, synthetic scavengers of ROS and antioxidants are to reduce arsenic-induced toxic effects.

Resveratrol (Rev) (trans-3,4',5-trihydroxystilbene) is isolated as a natural phytoalexin contained in wine and has several beneficial effects on health. Over the years, this molecule has received considerable attention for its antiinflammatory [11], antiviral [12], and antioxidant properties [13-15], as well as its ability to increase lifespan in lower organisms and improve general health in mammals [16]. 
The main target organs of resveratrol are the liver and kidney, as has been demonstrated in pharmacokinetic and pharmacodynamic studies [17]. Resveratrol exerts hepatoprotective activity against ethanol- and thioacetamide-induced acute liver damage in rats [18]. Systemic administration of resveratrol has since been shown to inhibit the initiation and growth of tumors in a wide variety of rodent cancer types [19]. Accumulating evidence also indicates that resveratrol has the capacity to exert sensitization effects when it is used in combination with cytotoxic drugs in drug-resistant tumor cells $[20,21]$.

Although the beneficial properties of resveratrol have been well defined, the mechanisms by which resveratrol protects the liver against the cytotoxic effects of $\mathrm{As}_{2} \mathrm{O}_{3}$ are not known. Therefore, the present study was undertaken to evaluate whether or not resveratrol can ameliorate the toxic effects of $\mathrm{As}_{2} \mathrm{O}_{3}$ in terms of recovery in biochemical variables indicative of oxidative stress, tissue injuries, and reduction in liver arsenic burden. These findings could provide a better understanding of the mechanisms of action of resveratrol in modulating $\mathrm{As}_{2} \mathrm{O}_{3}$-induced hepatic dysfunction and provide a rationale for further clinical study of resveratrol used in combination with $\mathrm{As}_{2} \mathrm{O}_{3}$ during chemotherapy or as a protective agent after $\mathrm{As}_{2} \mathrm{O}_{3}$ exposure.

\section{Materials and Methods}

2.1. Materials. $\mathrm{As}_{2} \mathrm{O}_{3}$ parenteral solution $(10 \mathrm{mg} / \mathrm{mL})$ was obtained from Harbin Yida Pharmaceutical Company Ltd. (Harbin, China). Resveratrol was provided by Sigma-Aldrich (St. Louis, MO, USA). Kits used for the detection of superoxide dismutase (SOD), catalase (CAT), glutathione peroxidase (GPX), malondialdehyde (MDA), glutathione (GSH), and glutathione disulfide (GSSG) were purchased from Jiancheng Bioengineering Institute (Nanjing, China). All other chemicals used were of the highest purity commercially available and purchased from Shanghai Biochemical and Beijing Chemical Co. Triple distilled water was used throughout the study to avoid metal contamination and for the preparation of reagents and buffers used for various biochemical assays.

2.2. Animals and Treatment. As the pharmacokinetic profiles of drugs in cats and humans are similar, cats are suitable for pharmacology and toxicology studies $[22,23]$. The study was performed using healthy Chinese Dragon-Li cats (12 males and 12 females) maintained in air-conditioned rooms at $21 \pm$ $4^{\circ} \mathrm{C}$. The cats were housed in individual stainless steel cages (during experimental phases). Weights and ages ranged from $2.8-3.5 \mathrm{~kg}$ to $1.5-2.0$ years, respectively.

All animals were randomly divided into four groups: control, $\mathrm{As}_{2} \mathrm{O}_{3}$-treated, $\mathrm{As}_{2} \mathrm{O}_{3}+$ resveratrol-treated, and resveratrol-treated. All of the treatments used in the study were administered via the foreleg vein on alternate days for 3 days (i.e., days 1, 3, and 5) with measurements made on the 6th day. Cats were treated as follows: in the control group they were injected with $10 \mathrm{~mL} / \mathrm{kg}$ physiological saline $(0.9 \%)$; in the $\mathrm{As}_{2} \mathrm{O}_{3}$ group they were treated with $\mathrm{As}_{2} \mathrm{O}_{3}(1 \mathrm{~mL} / \mathrm{kg})$; in the $\mathrm{As}_{2} \mathrm{O}_{3}+$ resveratrol $(3 \mathrm{~mL} / \mathrm{kg})$ group they were given resveratrol $(3 \mathrm{~mL} / \mathrm{kg}) 1 \mathrm{~h}$ before $\mathrm{As}_{2} \mathrm{O}_{3}$ administration.
The resveratrol "control" group received three doses of resveratrol alone $(3 \mathrm{~mL} / \mathrm{kg})$.

The selection of a single dose of resveratrol was based on previous published reports, where a dose of $3 \mathrm{~mL} / \mathrm{kg}$ was reported to be effective in preventing diverse biological and pharmacological properties [24].

Twenty-four hours after the last injection, all cats were killed by an overdose of pentobarbital sodium. Blood was collected and liver was rinsed in cold saline and used for evaluating various biochemical variables as well as arsenic concentrations. All study procedures were approved by Ethical Review Committees at the Northeast Agricultural University, China.

2.3. Preparation of Plasma and Liver Parameters. Some of the blood samples were collected into evacuated tubes containing heparinic solution as anticoagulant and then centrifuged at $3000 \mathrm{~g}$ for $10 \mathrm{~min}$. The activities of alanine aminotransferase (ALT) and aspartate aminotransferase (AST) and the levels of total bilirubin and cholesterol were detected using a UniCel DxC800 Synchron chemistry system (Bekman, USA).

2.4. Collection of Liver Samples and Biochemical Determination. Liver tissues were rapidly excised and homogenized in phosphate-buffered saline $\mathrm{pH} 7.4$ using an Ultrathurax T25 Homogenisator. After centrifugation at $10,000 \mathrm{~g}$ for $10 \mathrm{~min}$ at $4^{\circ} \mathrm{C}$, the supernatant was used for biochemical determination. The MDA, GSH, and GSSG levels, hepatic proteins, and SOD, CAT, and GPX activities in tissue were determined according to the manufacturer's instructions. The $\mathrm{GSH} / \mathrm{GSSG}$ ratio was calculated as follows: ratio $=[(\mathrm{GSH})-$ 2(GSSG)]/(GSSG).

2.5. Measurement of ROS Level in Liver. The amount of ROS in liver was measured by the method of $2^{\prime}, 7^{\prime}$ dichlorofluorescein diacetate, which is converted into highly fluorescent dichlorofluorescein by cellular peroxides (including hydrogen peroxide). The assay was performed as described in the literature [25]. Fluorescence was determined at $488 \mathrm{~nm}$ excitation and $525 \mathrm{~nm}$ emission wavelength, using a fluorescence plate reader (Perkin-Elmer, LS-55, Buckinghamshire, UK).

2.6. Morphological Examination. Liver tissues from cats were fixed in $10 \%$ formaldehyde for overnight at $37^{\circ} \mathrm{C}$. Tissues were cut into blocks of $3 \mathrm{~mm}$ thickness. Blocks were then embedded in paraffin. Sections ( $5 \mu \mathrm{m}$ thickness) were cut in the coronal plane and stained with hematoxylin and eosin. Morphological examination was conducted under a light microscope (BX-FM: Olympus Corp, Tokyo, Japan).

2.7. Determination of Total Arsenic in the Liver. A liver tissue sample of approximately $0.5 \mathrm{~g}$ was digested in a solution consisting of a mixture of $\mathrm{HNO}_{3}-\mathrm{HCLO}_{4}$ for 2 days at $130^{\circ} \mathrm{C}$. After $\mathrm{HNO}_{3}$ was removed by evaporation, digested samples were diluted with deionized water. Arsenic concentrations were measured using atomic fluorescence spectrometry (AFS930, Beijing Jitian Instrument Company, Beijing, China) [26]. 


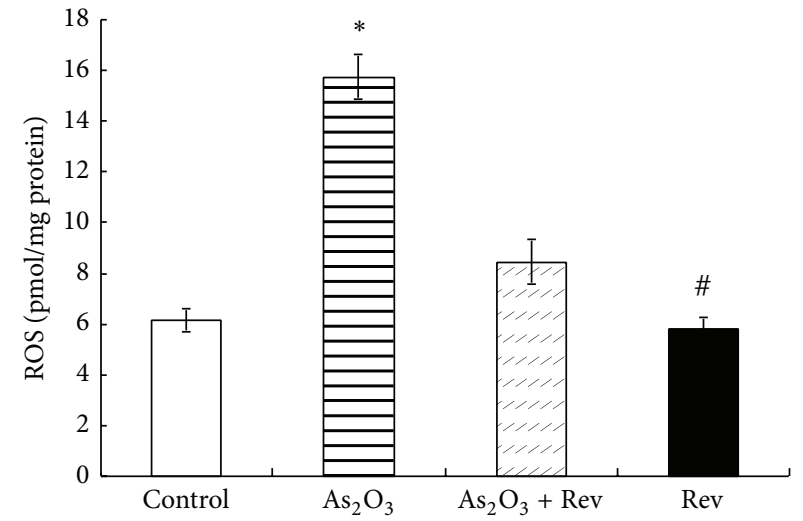

(a)

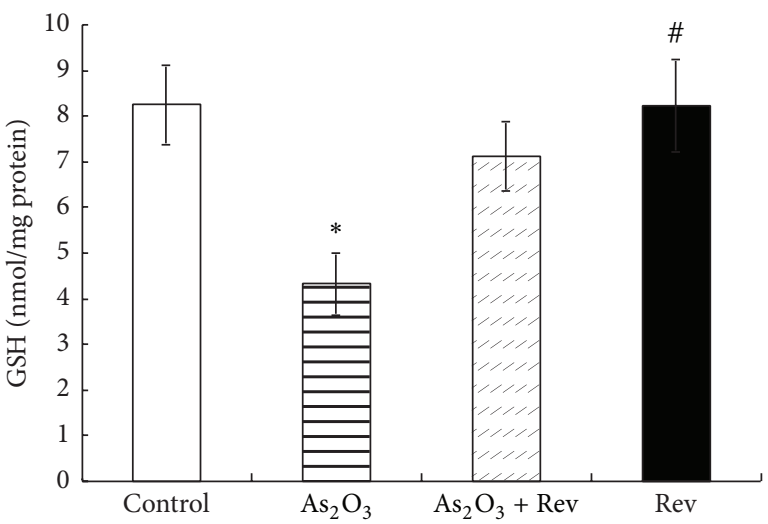

(b)

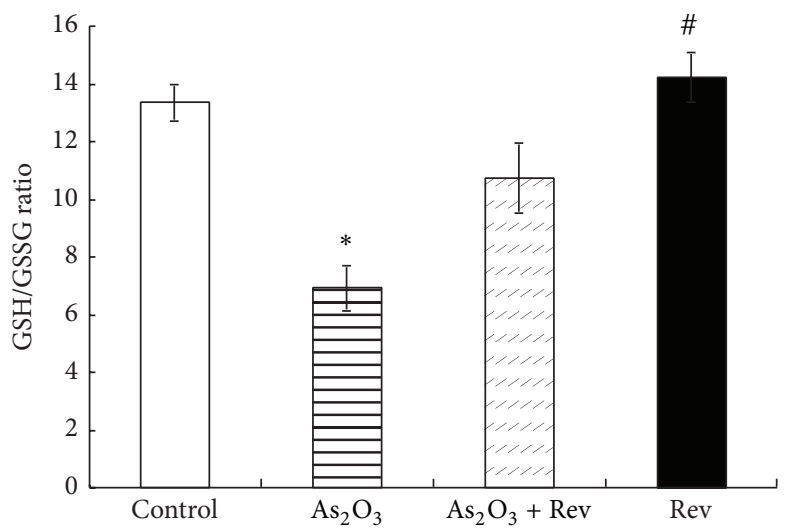

(c)

FIGURE 1: Arsenic-induced change in ROS, GSH, and GSH/GSSG ratio in liver and their response to pretreatment with resveratrol. Values are mean \pm SEM; ${ }^{*} P<0.05$ versus control group and ${ }^{\#} \mathrm{P}<0.05$ versus $\mathrm{As}_{2} \mathrm{O}_{3}$-treated group.

2.8. Statistical Analysis. Data represent the mean \pm SEM. Statistical analyses were undertaken by one-way ANOVA and the Student's $t$-test. A two-tailed $P<0.05$ was considered as being significant.

\section{Results}

The liver ROS level increased on arsenic exposure (Figure 1(a)). Pretreatment with resveratrol was beneficial in significantly reducing tissue ROS levels in the $\mathrm{As}_{2} \mathrm{O}_{3}$-treated group.

We analyzed the overall levels of GSH and GSSG in liver and calculated their ratio and found that $\mathrm{As}_{2} \mathrm{O}_{3}$ treatment significantly reduced the levels of GSH (Figure 1(b)) and the GSH/GSSG ratio (Figure 1(c)), whereas resveratrol treatment attenuated this reduction. Treatment with resveratrol alone did not cause any significant changes in the GSH/GSSG ratio relative to the control.

Figure 2(a) shows the effect of resveratrol on hepatic MDA levels. We found a significant increase in liver MDA after arsenic exposure. Pretreatment with resveratrol resulted in a pronounced decrease in MDA level relative to arsenic exposed animals, suggesting a beneficial role of the resveratrol on lipid peroxidation.
Figure 2 depicts the effect of pretreatment with resveratrol on the antioxidant enzyme systems SOD (Figure 2(b)), GPX (Figure 2(c)), and CAT (Figure 2(d)). There was a significant depletion of SOD, GPX, and CAT activity after arsenic exposure. Treatment with resveratrol prevented the depletion of SOD, GPX, and CAT activity.

Treatment with arsenic caused a significant increase in the total bilirubin, cholesterol, AST, and ALT levels, relative to the control (Table 1). However, treatment with resveratrol alone did not cause any significant changes in the activities of AST and ALT as compared with the control; pretreatment with resveratrol resulted in recovery in the above-mentioned biochemical variables.

The biochemical alterations mentioned above could be correlated with the histological changes in the liver shown in Figure 3. Histopathology of liver in the control group revealed a normal structure with a regular arrangement of hepatocytes with clearly visible nuclei and a characteristic pattern of hexagonal lobules (Figure 3(a)). After $\mathrm{As}_{2} \mathrm{O}_{3}$ treatment the liver exhibited serious pathological alterations such as the presence of increased cytoplasmic vacuolization, focal necrosis, and inflammatory cell infiltration (Figures 3(b) and 3(c)). The livers of resveratrol-treated cats (Figure 3(d)) showed good protection against hepatocellular necrosis, with 


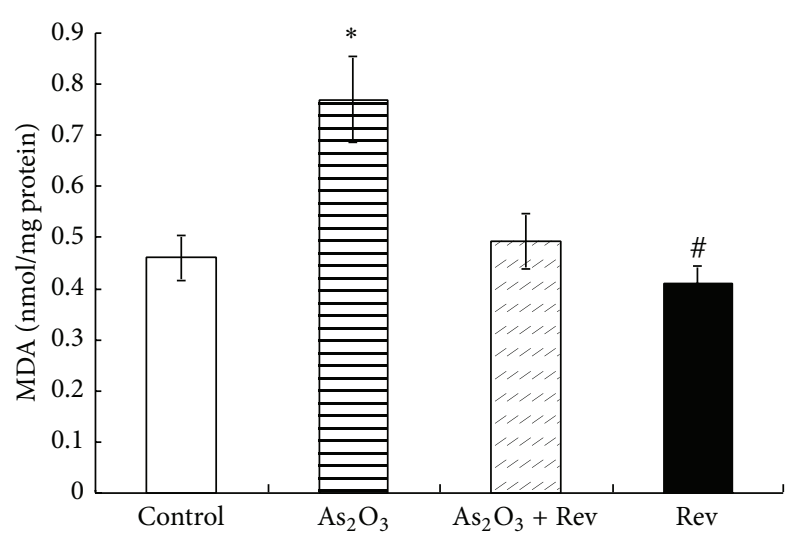

(a)

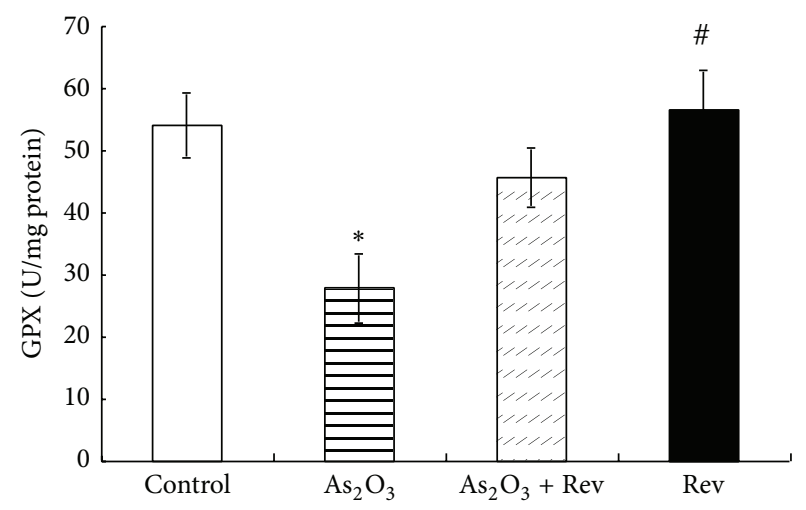

(c)

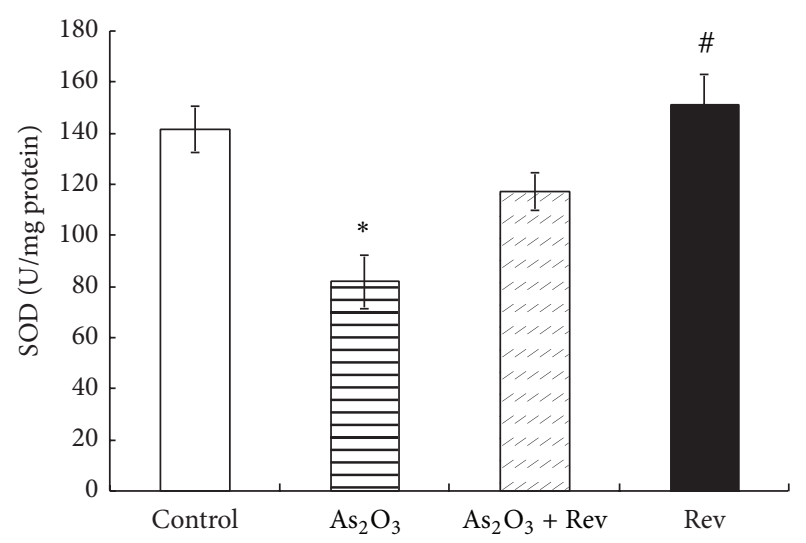

(b)

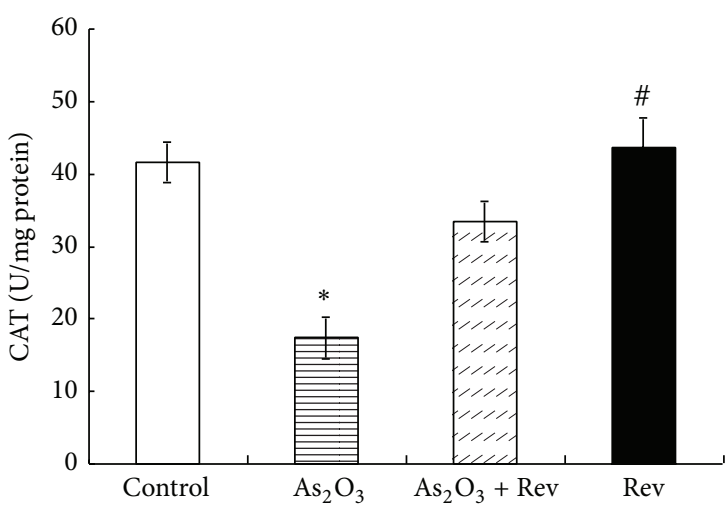

(d)

FIgURE 2: Arsenic-induced changes in SOD, GPX, CAT, and MDA in liver and their response to pretreatment with resveratrol. Values are mean \pm SEM; ${ }^{*} P<0.05$ versus control group and ${ }^{\#} P<0.05$ versus $\mathrm{As}_{2} \mathrm{O}_{3}$-treated group.

TABLE 1: The effect of resveratrol on $\mathrm{As}_{2} \mathrm{O}_{3}$-induced changes in serum biochemical parameters.

\begin{tabular}{lcccc}
\hline Treatments & Control & $\mathrm{As}_{2} \mathrm{O}_{3}$ & $\mathrm{As}_{2} \mathrm{O}_{3}+\mathrm{Rev}$ & $\mathrm{Rev}$ \\
\hline ALT $(\mathrm{U} / \mathrm{L})$ & $30.75 \pm 3.86$ & $83.50 \pm 4.65^{*}$ & $40.13 \pm 3.84^{* *}$ & $33.50 \pm 6.25$ \\
AST $(\mathrm{U} / \mathrm{L})$ & $38.75 \pm 4.34$ & $82 \pm 7.16^{*}$ & $48.75 \pm 4.99^{* *}$ & $34.50 \pm 7.33$ \\
Bilirubin $(\mu \mathrm{mol} / \mathrm{L})$ & $0.65 \pm 0.21$ & $2.03 \pm 0.16^{*}$ & $1.10 \pm 0.23^{* *}$ & $0.61 \pm 0.30$ \\
Cholesterol $(\mu \mathrm{mol} / \mathrm{L})$ & $2.15 \pm 0.28$ & $4.15 \pm 0.49^{*}$ & $2.35 \pm 0.36^{* *}$ & $2.04 \pm 0.53$ \\
\hline
\end{tabular}

Data are mean \pm SEM. ${ }^{*} P<0.01$ versus control group and ${ }^{* *} P<0.05$ versus $\mathrm{As}_{2} \mathrm{O}_{3}$-treated group.

a regular arrangement of hepatocytes and a slight cytoplasmic vacuolization around the central vein; hepatocytes of animals treated only with resveratrol had a normal morphology (data not shown).

Figure 4 shows the effect of pretreatment with resveratrol on arsenic concentrations in liver. Exposure to arsenic resulted in a significant increase in the arsenic concentration of the liver relative to the control. Administration of resveratrol significantly reduced the liver arsenic concentration.

\section{Discussion}

The mechanisms by which $\mathrm{As}_{2} \mathrm{O}_{3}$ causes hepatic dysfunction are not yet completely understood, but inducting the production ROS in tissues is one of the reasons [27, 28].
The amount of ROS in cells is dependent on both the production of ROS by the mitochondrial electron transport chain and their removal by ROS-detoxifying enzymes. Recently, some researchers have evaluated the effects of arsenic intermediate metabolites (monomethylarsonous acid, $\mathrm{MMA}^{\mathrm{III}}$, and trivalent dimethylarsinous acid, $\mathrm{DMA}^{\mathrm{III}}$ ) on the induction of ROS. It has been clearly confirmed that the generation of ROS is specifically induced in the endoplasmic reticulum by exposure to $\mathrm{DMA}^{\mathrm{III}}$, while previous studies have shown that MMA ${ }^{\mathrm{III}}$ induces ROS generation specifically through inhibition of the activities of complexes II and IV in mitochondria [29, 30]. In accordance with previous study, it was observed in our research that ROS level was markedly increased after arsenic exposure [31]. However, the role of resveratrol in mediating hepatic dysfunction induced 


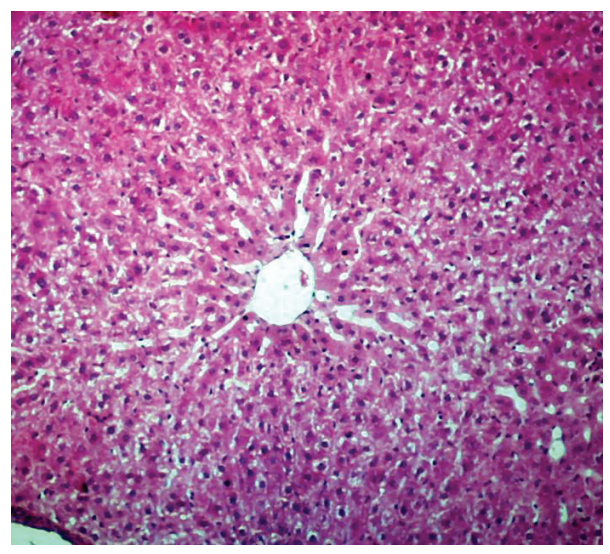

(a)

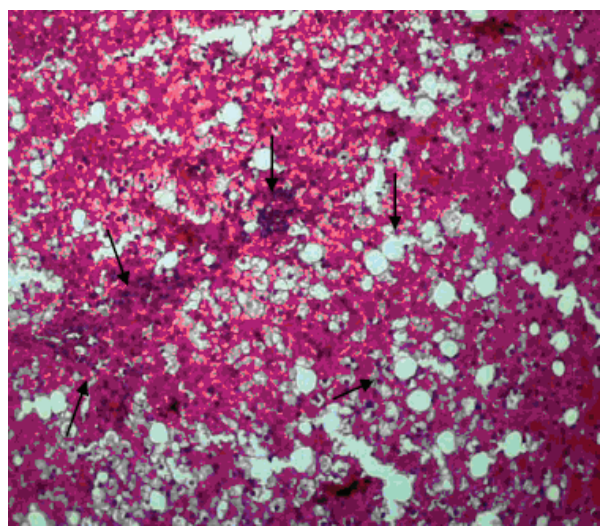

(c)

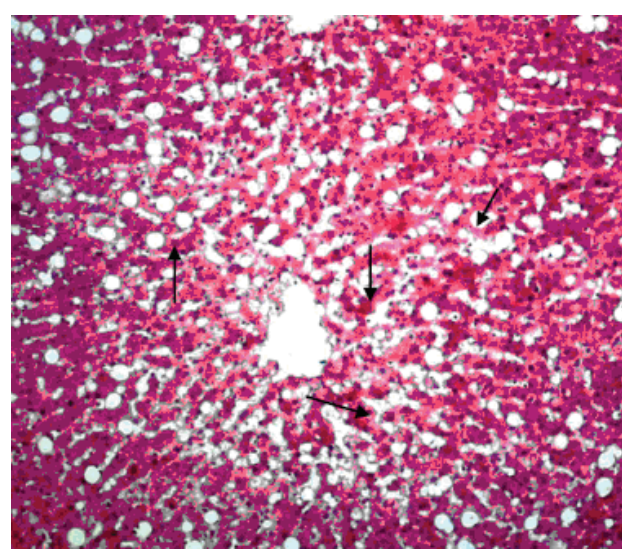

(b)

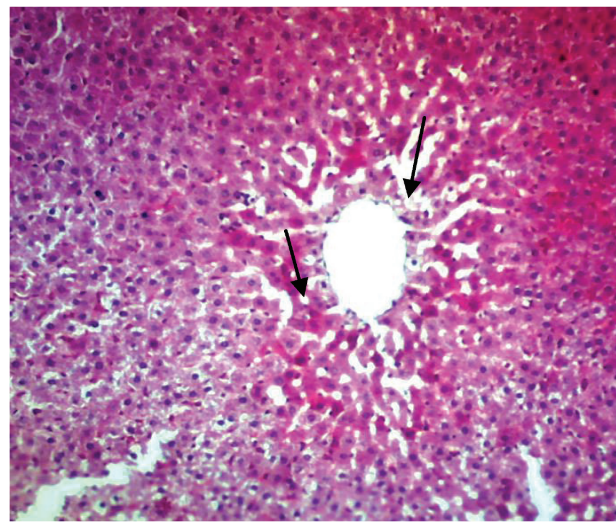

(d)

Figure 3: Liver histology in the control animals (a), $\mathrm{As}_{2} \mathrm{O}_{3}$ group (b) and (c), and $\mathrm{As}_{2} \mathrm{O}_{3}+$ resveratrol group (d) (H\&E, $\left.\times 100\right)$. Increased cytoplasmic vacuolization, focal necrosis, and inflammatory cell infiltration were noted in (b) and (c). (d) showed slight cytoplasmic vacuolization.

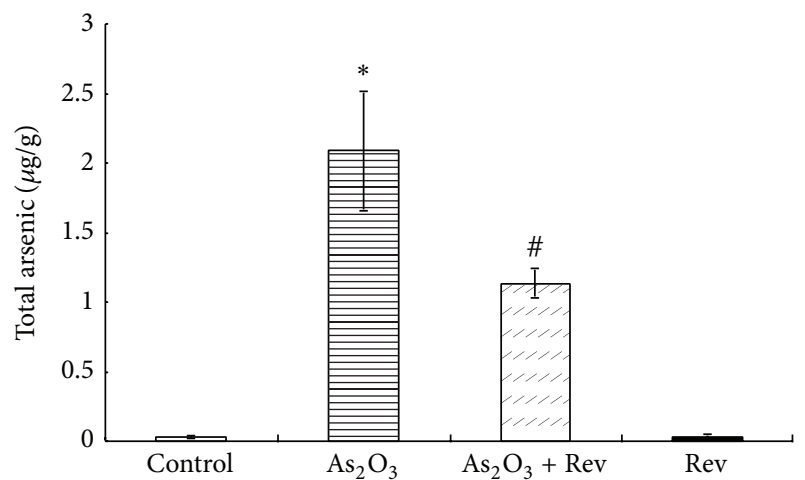

FIGURE 4: Total arsenic retention in cat livers. Data are mean \pm SEM; ${ }^{*} P<0.01$ versus control group and ${ }^{\#} P<0.05$ versus $\mathrm{As}_{2} \mathrm{O}_{3}$-treated group.

by $\mathrm{As}_{2} \mathrm{O}_{3}$ is not well understood. Our study demonstrated that the addition of resveratrol improved the protection of the liver against the cytotoxic effects of this agent, including hepatic function; this was suggested by liver parameters and liver histological changes. The protective effects of resveratrol against $\mathrm{As}_{2} \mathrm{O}_{3}$ may be attributable to its ability to modulate cellular redox. This suggestion is supported by the finding that resveratrol treatment persevered the activities of SOD, CAT, and GPX, inhibited $\mathrm{As}_{2} \mathrm{O}_{3}$-induced increases in ROS production, and attenuated $\mathrm{As}_{2} \mathrm{O}_{3}$-induced reduction in the ratio of GSH/GSSG in liver. MDA (the end product of lipid peroxidation) is known as an index that can be used to monitor the oxidative damage. However, in the present study pretreatment with resveratrol induced the marked decrease in MDA levels relative to the $\mathrm{As}_{2} \mathrm{O}_{3}$-treated group, which might be attributable to the above findings. These data related to the beneficial effects of resveratrol could be explained by the important role that it plays in improving the activity of mitochondrial complexes I, III, and IV [32], as well as imbalance in the levels of ROS and antioxidants [33, 34]. Also, it has been proposed that resveratrol indirectly activates PGC- $1 \alpha$, which can regulate mitochondrial energetics and induce the expression of many ROS-detoxifying enzymes including SOD, CAT, and GPX $[35,36]$. As resveratrol can effectively protect liver by inhibiting $\mathrm{As}_{2} \mathrm{O}_{3}$-induced $\mathrm{ROS}$ production, it may decrease the risk of cancer patients developing secondary malignancies. Since chemotherapy can 
induce increased ROS production which causes genetic instability, then the risk of leukemia and cancer will be increased [37].

One of the most interesting observations in our study was the ability of resveratrol to reduce the concentration of arsenic in the target tissue, which may play a crucial role in its hepatoprotective effect. Protection against arsenic in human cells has been shown to be associated with GSH-dependent efflux from the cell [38]. Depleting GSH has been reported to increase sensitivity to arsenic and its retention in mammalian cells $[39,40]$. To explain our findings, we hypothesize that GSH may be maintained in hepatocytes after pretreatment with resveratrol, as suggested by the concentration of GSH in liver in our results [41].

Furthermore, it is plausible that improving the redox status by pretreatment with resveratrol may play an important role in enhancing the efflux of arsenic in our study. Conversely, resveratrol has been shown to impair the efflux of cytotoxic drugs in human hepatoma cells, suggesting competitive inhibition of arsenic-transport membrane protein by resveratrol in tumor cells. In addition, combination of resveratrol with $\mathrm{As}_{2} \mathrm{O}_{3}$ may act as a remedial therapy for protecting $\mathrm{As}_{2} \mathrm{O}_{3}$-treated subjects and individuals exposed to arsenicals from the hepatotoxicity of $\mathrm{As}_{2} \mathrm{O}_{3}$ as well as acting as an anticancer agent itself.

In summary, findings from the present and other studies suggest that pharmacological modulators of the redox pathway, such as resveratrol, may be feasible agents for ameliorating $\mathrm{As}_{2} \mathrm{O}_{3}$-induced hepatotoxicity and hepatic dysfunction. Our data support the notion that the protective properties of resveratrol against $\mathrm{As}_{2} \mathrm{O}_{3}$-induced oxidative stress and hepatotoxicity were realized through decreasing the retention of arsenic and improving the redox status of liver tissue. However, further clinical studies are needed to provide data on the clinical use of resveratrol in cases involving arsenic exposure and in an APL patient model.

\section{Conflict of Interests}

The authors declare that there is no conflict of interests regarding the publication of this paper.

\section{Authors' Contribution}

Zhigang Zhang, Li Gao, and Yanyan Cheng have contributed equally to this study.

\section{Acknowledgments}

This study was supported by National Science Foundation Committee of China (31101868), the Program for New Century Excellent Talents in Heilongjiang Provincial University (1253-NCET-007), and the Open Projects of Key Laboratory of Feed Science, College of Heilongjiang Province.

\section{References}

[1] S. J. Chen, G. B. Zhou, X. W. Zhang, J. H. Mao, H. De Thé, and Z. Chen, "From an old remedy to a magic bullet: molecular mechanisms underlying the therapeutic effects of arsenic in fighting leukemia," Blood, vol. 117, no. 24, pp. 6425-6437, 2011.

[2] A. Jain, A. Yadav, A. I. Bozhkov, V. I. Padalko, and S. J. S. Flora, "Therapeutic efficacy of silymarin and naringenin in reducing arsenic-induced hepatic damage in young rats," Ecotoxicology and Environmental Safety, vol. 74, no. 4, pp. 607-614, 2011.

[3] B. Chen, L. L. Arnold, S. M. Cohen, D. J. Thomas, and X. C. Le, "Mouse arsenic (+3 oxidation state) methyltransferase genotype affects metabolism and tissue dosimetry of arsenicals after arsenite administration in drinking water," Toxicological Sciences, vol. 124, no. 2, pp. 320-326, 2011.

[4] L. Mathew, A. Vale, and J. E. Adcock, "Arsenical peripheral neuropathy," Practical Neurology, vol. 10, no. 1, pp. 34-38, 2010.

[5] A. Anwar-Mohamed, G. Abdelhamid, I. E. A. Amara, and A. O. S. El-Kadi, "Differential modulation of aryl hydrocarbon receptor regulated enzymes by arsenite in the kidney, lung, and heart of C57BL/6 mice," Archives of Toxicology, vol. 86, no. 6, pp. 897-910, 2012.

[6] M. Messarah, F. Klibet, A. Boumendjel et al., "Hepatoprotective role and antioxidant capacity of selenium on arsenic-induced liver injury in rats," Experimental and Toxicologic Pathology, vol. 64, no. 3, pp. 167-174, 2012.

[7] L. Benramdane, M. Accominotti, L. Fanton, D. Malicier, and J. Vallon, "Arsenic speciation in human organs following fatal arsenic trioxide poisoning-a case report," Clinical Chemistry, vol. 45, no. 2, pp. 301-306, 1999.

[8] M. K. Paul, R. Kumar, and A. K. Mukhopadhyay, "Dithiothreitol abrogates the effect of arsenic trioxide on normal rat liver mitochondria and human hepatocellular carcinoma cells," Toxicology and Applied Pharmacology, vol. 226, no. 2, pp. 140152, 2008.

[9] S. Ghosh, S. R. Dungdung, S. T. Chowdhury et al., "Encapsulation of the flavonoid quercetin with an arsenic chelator into nanocapsules enables the simultaneous delivery of hydrophobic and hydrophilic drugs with a synergistic effect against chronic arsenic accumulation and oxidative stress," Free Radical Biology and Medicine, vol. 51, no. 10, pp. 1893-1902, 2011.

[10] C. Loguercio and A. Federico, "Oxidative stress in viral and alcoholic hepatitis," Free Radical Biology and Medicine, vol. 34, no. 1, pp. 1-10, 2003.

[11] X. Zhu, Q. Liu, M. Wang et al., "Activation of Sirt1 by resveratrol inhibits TNF- $\alpha$ induced inflammation in fibroblasts.", PloS ONE, vol. 6, no. 11, Article ID e27081, 2011.

[12] O. F. Dyson, L. R. Walker, A. Whitehouse, P. P. Cook, and S. M. Akula, "Resveratrol inhibits KSHV reactivation by lowering the levels of cellular Egr-1," PLoS ONE, vol. 7, no. 3, Article ID e33364, 2012.

[13] İ. Gülçin, "Antioxidant activity of food constituents: an overview," Archives of Toxicology, vol. 86, pp. 345-391, 2012.

[14] W. Q. Zhang, C. Y. Yao, M. Ge et al., "Attenuation of arsenic retention by resveratrol in lung of arsenic trioxide-exposed rats," Environmental Toxicology and Pharmacology, vol. 36, no. 1, pp. 35-39, 2013.

[15] M. Yu, J. Xue, Y. Li et al., "Resveratrol protects against arsenic trioxide-induced nephrotoxicity by facilitating arsenic metabolism and decreasing oxidative stress," Archives of Toxicology, vol. 87, no. 6, pp. 1025-1035, 2013.

[16] J. A. Baur, K. J. Pearson, N. L. Price et al., "Resveratrol improves health and survival of mice on a high-calorie diet," Nature, vol. 444, no. 7117, pp. 337-342, 2006. 
[17] H. Colom, I. Alfaras, M. Maijó, M. E. Juan, and J. M. Planas, "Population pharmacokinetic modeling of trans-resveratrol and its glucuronide and sulfate conjugates after oral and intravenous administration in rats," Pharmaceutical Research, vol. 28, no. 7, pp. 1606-1621, 2011.

[18] A. Kasdallah-Grissa, B. Mornagui, E. Aouani et al., "Resveratrol, a red wine polyphenol, attenuates ethanol-induced oxidative stress in rat liver," Life Sciences, vol. 80, no. 11, pp. 1033-1039, 2007.

[19] S. Garvin, K. Öllinger, and C. Dabrosin, "Resveratrol induces apoptosis and inhibits angiogenesis in human breast cancer xenografts in vivo," Cancer Letters, vol. 231, no. 1, pp. 113-122, 2006.

[20] T. Kubota, Y. Uemura, M. Kobayashi, and H. Taguchi, "Combined effects of resveratrol and paclitaxel on lung cancer cells," Anticancer Research, vol. 23, no. 5 A, pp. 4039-4046, 2003.

[21] Y. A. Rezk, S. S. Balulad, R. S. Keller, and J. A. Bennett, "Use of resveratrol to improve the effectiveness of cisplatin and doxorubicin: Study in human gynecologic cancer cell lines and in rodent heart," The American Journal of Obstetrics and Gynecology, vol. 194, no. 5, pp. e23-e26, 2006.

[22] B. Hughes, B. R. Madan, and J. R. Parratt, "Polymyxin B sulphate protects cats against the haemodynamic and metabolic effects of E. coli endotoxin," The British Journal of Pharmacology, vol. 74, no. 3, pp. 701-707, 1981.

[23] J. M. Giraudel, A. Diquelou, V. Laroute, P. Lees, and P. Toutain, "Pharmacokineti/pharmacodynamic modelling of NSAIDs in a model of reversible inflammation in the cat," British Journal of Pharmacology, vol. 146, no. 5, pp. 642-653, 2005.

[24] M. Mokni, S. Elkahoui, F. Limam, M. Amri, and E. Aouani, "Effect of resveratrol on antioxidant enzyme activities in the brain of healthy rat," Neurochemical Research, vol. 32, no. 6, pp. 981-987, 2007.

[25] D. J. Socci, K. B. Bjugstad, H. C. Jones, J. V. Pattisapu, and G. W. Arendash, "Evidence that oxidative stress is associated with the pathophysiology of inherited hydrocephalus in the H-Tx rat model," Experimental Neurology, vol. 155, no. 1, pp. 109-117, 1999.

[26] X. Cui, Y. Kobayashi, T. Hayakawa, and S. Hirano, "Arsenic speciation in bile and urine following oral and intravenous exposure to inorganic and organic arsenics in rats," Toxicological Sciences, vol. 82, no. 2, pp. 478-487, 2004.

[27] S. J. Flora, "Arsenic-induced oxidative stress and its reversibility," Free Radical Biology \& Medicine, vol. 51, no. 2, pp. 257-281, 2011.

[28] L. Wang, M. Kou, C. Weng, L. Hu, Y. Wang, and M. Wu, "Arsenic modulates heme oxygenase-1, interleukin-6, and vascular endothelial growth factor expression in endothelial cells: roles of ROS, NF - $\mathrm{kB}$, and MAPK pathways," Archives of Toxicology, vol. 86, no. 6, pp. 879-896, 2012.

[29] H. Naranmandura, S. Xu, S. Koike et al., "The endoplasmic reticulum is a target organelle for trivalent dimethylarsinic acid $\left(\mathrm{DMA}^{I I I}\right)$-induced cytotoxicity," Toxicology and Applied Pharmacology, vol. 260, no. 3, pp. 241-249, 2012.

[30] H. Naranmandura, S. Xu, T. Sawata et al., "Mitochondria are the main target organelle for trivalent monomethylarsonous acid (MMA III)-induced cytotoxicity," Chemical Research in Toxicology, vol. 24, no. 7, pp. 1094-1103, 2011.

[31] S. X. Liu, M. Athar, I. Lippai, C. Waldren, and T. K. Hei, "Induction of oxyradicals by arsenic: Implication for mechanism of genotoxicity," Proceedings of the National Academy of Sciences of the United States of America, vol. 98, no. 4, pp. 1643-1648, 2001.
[32] J. Zheng, L. Chen, H. Zhang, X. Hu, W. Kong, and D. Hu, "Resveratrol improves insulin resistance of catch-up growth by increasing mitochondrial complexes and antioxidant function in skeletal muscle," Metabolism, vol. 61, no. 7, pp. 954-965, 2012.

[33] R. Anderson and T. Prolla, "PGC- $1 \alpha$ in aging and anti-aging interventions," Biochimica et Biophysica Acta, vol. 1790, no. 10, pp. 1059-1066, 2009.

[34] B. Olas, P. Nowak, J. Kolodziejczyk, M. Ponczek, and B. Wachowicz, "Protective effects of resveratrol against oxidative/nitrative modifications of plasma proteins and lipids exposed to peroxynitrite," Journal of Nutritional Biochemistry, vol. 17, no. 2, pp. 96-102, 2006.

[35] E. L. Robb and J. A. Stuart, "Resveratrol interacts with estrogen receptor- $\beta$ to inhibit cell replicative growth and enhance stress resistance by upregulating mitochondrial superoxide dismutase," Free Radical Biology and Medicine, vol. 50, no. 7, pp. 821831, 2011.

[36] S. J. Park, F. Ahmad, A. Philp et al., "Resveratrol ameliorates aging-related metabolic phenotypes by inhibiting cAMP phosphodiesterases," Cell, vol. 148, no. 3, pp. 421-433, 2012.

[37] C. M. Diaz-Montero, Y. Wang, L. Shao et al., "The glutathione disulfide mimetic NOV-002 inhibits cyclophosphamideinduced hematopoietic and immune suppression by reducing oxidative stress," Free Radical Biology and Medicine, vol. 52, no. 9, pp. 1560-1568, 2012.

[38] E. M. Leslie, "Arsenic-glutathione conjugate transport by the human multidrug resistance proteins (MRPs/ABCCs)," Journal of Inorganic Biochemistry, vol. 108, pp. 141-149, 2012.

[39] M. W. Carew, H. Naranmandura, C. B. Shukalek, X. C. Le, and E. M. Leslie, "Monomethylarsenic diglutathione transport by the human multidrug resistance protein 1 (MRP1/ABCC1)," Drug Metabolism and Disposition, vol. 39, no. 12, pp. 2298-2304, 2011.

[40] P. Ong, S. Chan, and P. C. Ho, "Differential augmentative effects of buthionine sulfoximine and ascorbic acid in As2O3induced ovarian cancer cell death: oxidative stress-independent and -dependent cytotoxic potentiation," International Journal of Oncology, vol. 38, no. 6, pp. 1731-1739, 2011.

[41] S. Hassan-Khabbar, C. H. Cottart, D. Wendum et al., "Postischemic treatment by trans-resveratrol in rat liver ischemiareperfusion: a possible strategy in liver surgery," Liver Transplantation, vol. 14, no. 4, pp. 451-459, 2008. 


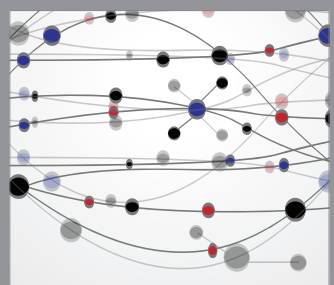

The Scientific World Journal
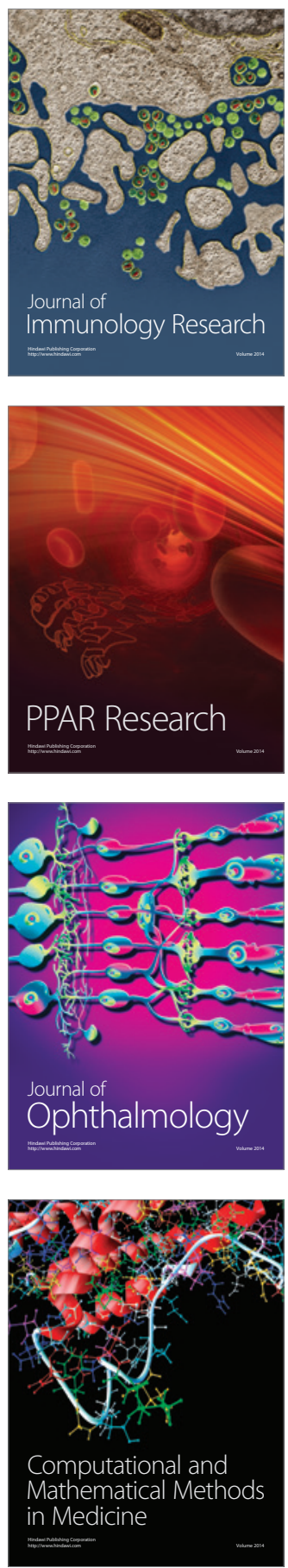

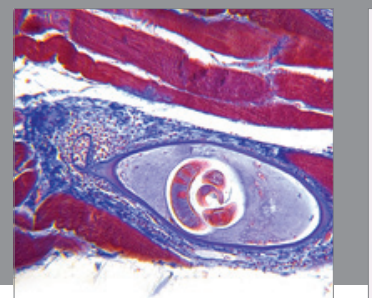

Gastroenterology

Research and Practice
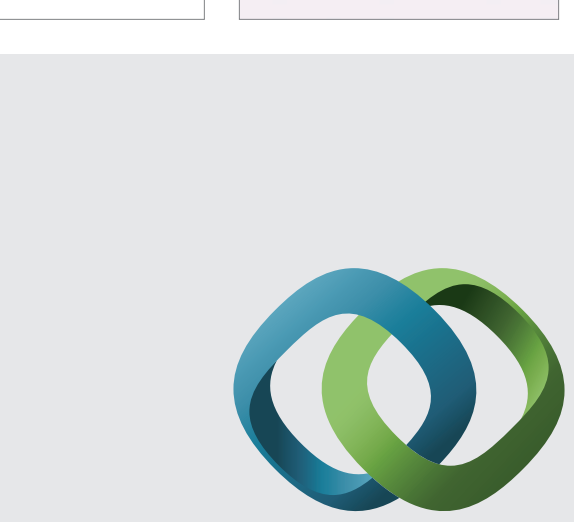

\section{Hindawi}

Submit your manuscripts at

http://www.hindawi.com
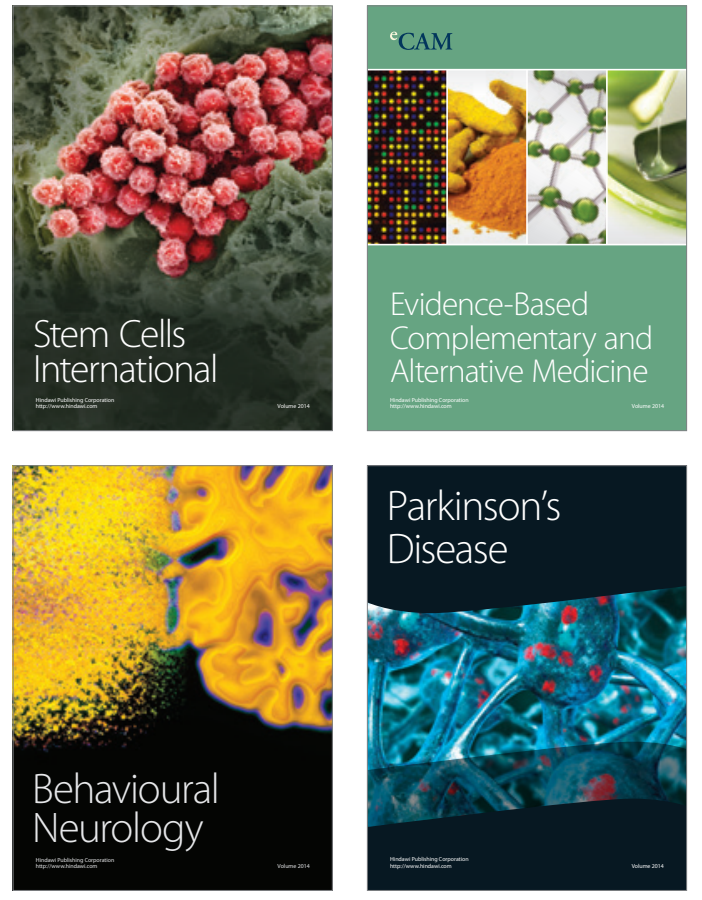
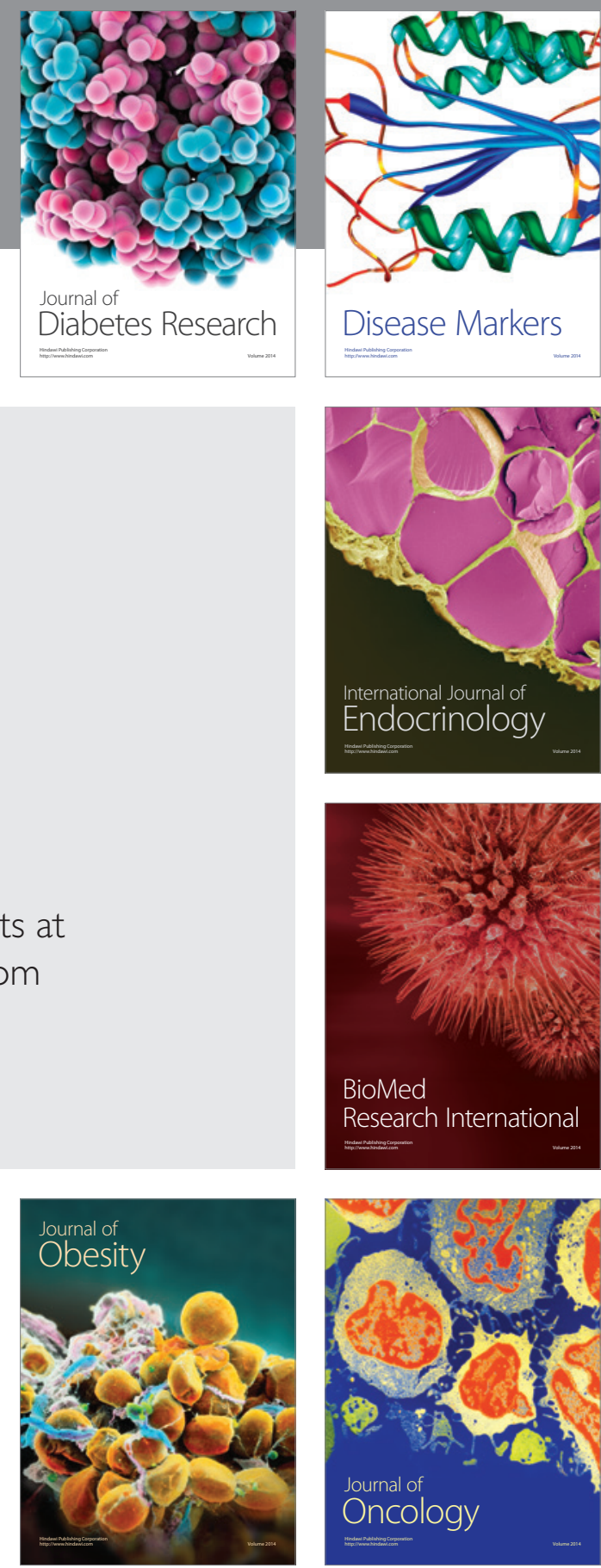

Disease Markers
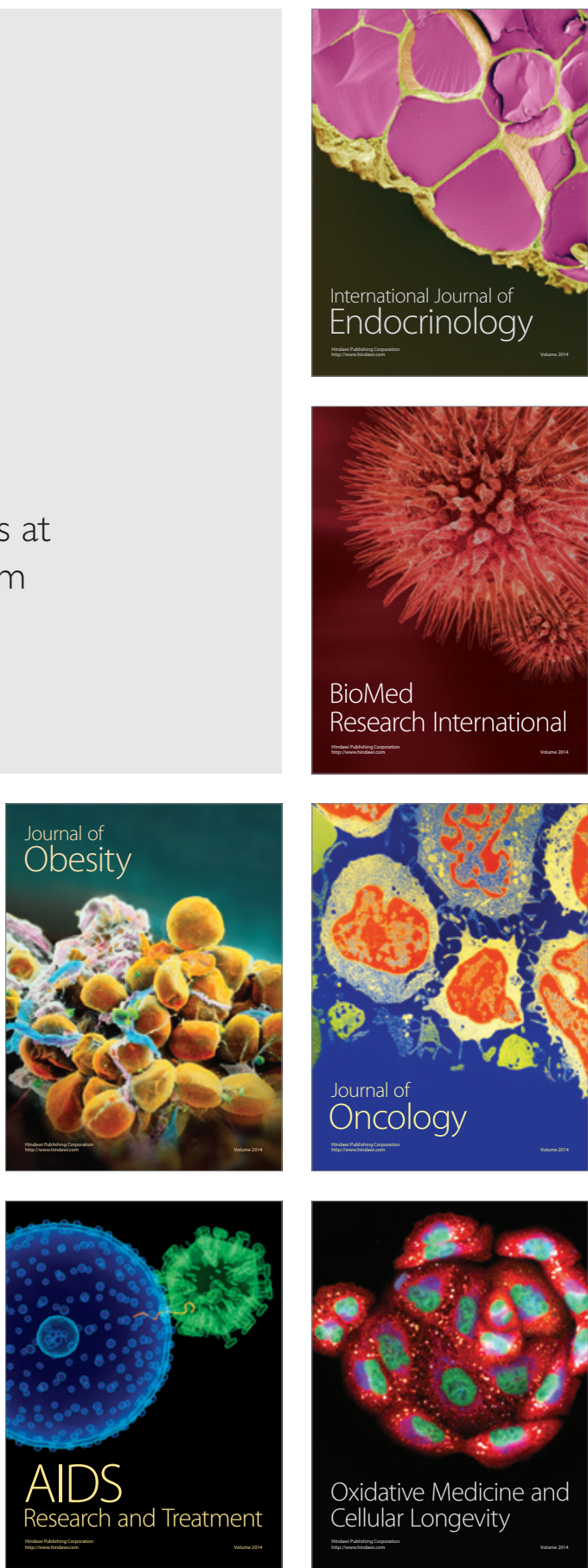